\title{
Hierarchical integration of communicative and spatial perspective-taking demands in sensorimotor control of referential pointing
}

\author{
Rui Liu a, Sara Bögels a, Geoffrey Bird b, c, W. Pieter Medendorp a, Ivan Toni a \\ a. Donders Institute for Brain, Cognition and Behaviour, Radboud University, the Netherlands. \\ b. Department of Experimental Psychology, University of Oxford, Oxford, UK. \\ c. Social, Genetic and Developmental Psychiatry Centre, Institute of Psychiatry, Psychology \& \\ Neuroscience, King's College London, London, UK.
}

\section{Abstract}

Recognised as a simple communicative behaviour, referential pointing is cognitively complex because it invites a communicator to consider an addressee's knowledge. Although we know referential pointing is affected by addressees' physical location, it remains unclear whether and how communicators' inferences about addressees' mental representation of the interaction space influence sensorimotor control of referential pointing. The Communicative Perspective-Taking task requires a communicator to point at one out of multiple referents either to instruct an addressee which one should be selected (communicative, COM) or to predict which one the addressee will select (non-communicative, NCOM), based on either which referents can be seen (Level-1 perspectivetaking, PT1) or how the referents were perceived (Level-2 perspective-taking, PT2) by the addressee. Communicators took longer to initiate the movements in PT2 than PT1 trials, and they held their pointing finger for longer at the referent in COM than NCOM trials. The novel findings of this study pertain to trajectory control of the pointing movements. Increasing both communicative and perspective-taking demands led to longer pointing trajectories, with an under-additive interaction between those two experimental factors. This finding suggests that participants generate communicative behaviours that are as informative as required, rather than overly exaggerated displays, by integrating communicative and perspective-taking information hierarchically during sensorimotor control.

Keywords: Perspective-taking; spatial representation; kinematics; social interaction; recipient design 
2 of 32

1

\section{Introduction}

Pointing one's finger to a location in space in order to signal a referent for an addressee is one of the biomechanically simpler instances of human communicative behaviour, yet referential pointing is cognitively complex: it invites communicators to consider the presumed knowledge of addressees, an instance of recipient design (Clark \& Murphy, 1982; Tomasello et al., 2007; Blokpoel et al., 2012). It has been argued that referential pointing is a fundamental human communicative behavior, relevant to understand other forms of human communication, with or without accompanying speech (McNeill, 1992; de Ruiter, 2000; Enfield et al., 2007; Tomasello et al., 2007; Tomasello, 2008; Liszkowski et al., 2012; de Ruiter et al., 2012; Cooperrider, 2016; Enfield \& Sidnell, 2017). Referential pointing provides an ecologically valid testing ground for understanding the integration of sociocognitive information with sensorimotor processing (Creem-Regehr et al., 2013; Murillo Oosterwijk et al., 2017; Winner et al., 2019; Pouw et al., 2020). Previous work has shown how communicators organize their pointing movements incorporating the physical location of addressees (Özyürek, 2002; Cleret de Langavant et al., 2011; Pezzulo et al., 2013; Murillo Oosterwijk et al., 2017; Winner et al., 2019). However, it remains unclear whether and how communicators' inferences about addressees' mental representation of the interaction space influence planning and control of referential pointing.

Inferring others' mental representation of space is conceptualized as spatial perspective-taking and it is differentiated in two levels, according to the cognitive demands involved (Salatas \& Flavell, 1976; Michelon \& Zacks, 2006; Kessler \& Rutherford, 2010; Surtees et al., 2013). Level-1 perspectivetaking is required to infer whether part of a visual scene can be seen by another observer. It relies on calculating another observer's line-of-sight in an egocentric frame of reference. Level-2 perspectivetaking is required to infer how a visual scene is perceived by another observer. It relies on transforming frames of reference between self and others, adopting an allocentric frame of reference. 
1 Brown-Schmidt \& Hanna, 2011; Clements-Stephens et al., 2013). Previous studies have examined

2 how interlocutors make use of perspective information in language comprehension and production,

3 e.g. by manipulating shared and privileged information (Director Task, Keysar et al., 2000; Barr,

4 2008; Brown-Schmidt \& Hanna, 2011). Those studies have largely focused on the behavioral

5 consequences (such as task accuracy, reaction times, adjective selection, eye gaze) of perspective-

6 taking and communication. It remains unclear whether and how perspective-taking and

7 communicative demands interface with sensorimotor processes during the production of a

8 communicative behavior. Here, we differentiate between three potential coupling mechanisms

9 between a communicator's sensorimotor system and the cognitive operations handling

10 communicative and perspective-taking demands.

11 We developed a Communicative Perspective Taking (CPT) task in which communicative and

12 perspective-taking demands were manipulated independently, in a full-factorial design. In this task,

13 a communicator and an addressee sit on the opposite side of a table. The communicator points to one

14 among a set of digital stimuli presented at different locations on the table, while facing the addressee.

15 A visual barrier is interposed between the addressee and the digital stimuli, allowing the

16 communicator full view of the stimuli and of the barrier, whereas the addressee can see only a subset

17 of the stimuli through the barrier. The communicator points either to instruct the addressee which

18 digital stimulus should be chosen, when the addressee does not know the target (communicative

19 pointing, COM), or to predict which stimulus the addressee will choose, when the addressee knows

20 the target (non-communicative pointing, NCOM). To decide which stimulus to point to, on each trial

21 the communicator has to spontaneously infer either which target stimulus can be seen by the

22 addressee through the barrier (level-1 perspective-taking, PT1), or which of the stimuli seen by the

23 addressee looks like the target when seen from the addressee's perspective (level-2 perspective-

24 taking, PT2). 
4 of 32

We recorded the kinematics of the communicator's right hand throughout the experiment and analysed temporal and spatial features of the pointing movements. Following previous studies, we considered kinematic features relevant to parameterize the sensorimotor processes of movement planning and execution (Becchio et al., 2010; Cleret de Langavant et al., 2011; Murillo Oosterwijk et al., 2017). Each pointing movement was segmented into four stages: planning, approach, holding, and returning, approximately corresponding to the "rest", "stroke", "hold" and "retraction" stages used in the analysis of co-speech gestures (McNeill, 1992; Kita et al., 1998). Temporally, we focused on the duration of the planning stage (i.e. the period between presentation of the stimuli and movement onset) and of the holding stage (i.e. the period between arrival at the end-position and onset of the return movement away from the end-position). Spatially, we computed displacement and variability of the approach trajectories, parameters known to index movement magnitude and movement corrections, respectively (Bays \& Wolpert, 2007; Körding \& Wolpert, 2006; Gallivan et al., 2018). Building on existing work, we expect to validate the current experimental setup by reproducing the observations that PT2 requires longer planning time than PT1 (Michelon \& Zacks, 2006; Kessler \& Rutherford, 2010; Surtees et al., 2016) and that communicative demands result in longer holding times and exaggerated pointing trajectories (Becchio et al., 2010; Cleret de Langavant et al., 2011; Peeters et al., 2015; Krishnan-Barman et al., 2017; Murillo Oosterwijk et al., 2017; Trujillo et al., 2020). The kinematic parameters considered in this study have been chosen to differentiate between three hypotheses on the mechanism coupling cognitive and sensorimotor systems during referential pointing (Table 1). Hypothesis 1 proposes that those systems are independent: a communicator first decides where to point, according to perspective-taking demands (Michelon \& Zacks, 2006; Kessler \& Rutherford, 2010; Surtees et al., 2016), and then plans and controls the movement according to communicative demands. This hypothesis predicts a null effect of perspective-taking on the bulk of the pointing trajectory and limits perspective-taking effects to planning time, while higher communicative demands would lead to more emphatic pointing trajectories, as shown previously 
1 (Cleret de Langavant et al., 2011; Murillo Oosterwijk et al., 2017; Winner et al., 2019). Hypothesis 2

2 proposes that perspective-taking effects, occurring during the determination of the pointing location

3 before movement onset, might leak into later stages of movement execution when the pointing finger

4 approaches the end-position (the "apex" in co-speech gesture literature), as communicators might

5 only consider accuracy of the pointing end-positions that directly determines the task performance.

6 Under the framework of Optimal Feedback Control (Todorov \& Jordan, 2002, 2003; Scott, 2004,

7 2016; Schwartz, 2016), deviations away from the predetermined forward kinematics (i.e. the

8 anticipatory internal model that specifies end-effectors and joint kinematics) will be corrected only

9 for the task-relevant dimensions. Specifically, the principle of minimum intervention of sensorimotor

10 control argues that only the end-position of the movement, instead of the whole trajectory, is

11 modified by the sensorimotor system, unless external perturbation while moving hampers task

12 performance (Todorov \& Jordan, 2003; Nashed et al., 2012; Keyser et al., 2017). This sensorimotor

13 coding mechanism would predict the leakage of perspective-taking into late stage movement

14 execution due to the control of end-position; and it would occur in parallel to an early effect of

15 communicative demand on the approach trajectory (Cleret de Langavant et al., 2011; Murillo

16 Oosterwijk et al., 2017; Winner et al., 2019). Hypothesis 3 proposes that communicators might bear

17 in mind the addressee's perspective as well as communicative demands, while planning and

18 controlling the pointing movements. This hypothesis predicts an under-additive interaction effect of

19 perspective-taking and communicative demands in the trajectory. The reason is that the more control

20 signals are present, the more noise emerges in the sensorimotor system (i.e. "signal-dependent

21 noise") (Harris \& Wolpert, 1998; Wolpert \& Ghahramani, 2000; Wolpert et al., 2003; Faisal et al.,

22 2008). Hypothesis 3 implies that the two types of cognitive demands might share a common coding

23 in the sensorimotor interface, allowing those different cognitive demands to be integrated to

24 generate more efficient control signals ("control policy" refers to internal rules on how anticipated 
6 of 32

1 consequences of a movement and real-time sensory information are used to generate motor

2 commands) (Todorov \& Jordan, 2002, 2003; Scott, 2004, 2016; Schwartz, 2016).

3

$4 \quad$ Table 1

5 Predictions on the timing of perspective-taking, communication and their interaction effects

6 according to Hypothesis $1 \sim 3$.

\begin{tabular}{lccc}
\hline & Planning (time) & Approach (trajectory) & Holding (time) \\
\hline Hypothesis 1 & PT2 > PT1 & Communication & COM > NCOM \\
Hypothesis 2 & PT2 > PT1 & Communication (early effect) & COM > NCOM \\
Hypothesis 3 & PT2 > PT1 & Perspective-taking (late effect) & \\
\hline
\end{tabular}

7

8 2. Methods

9 2.1. Participants

Thirty-eight right-handed healthy participants, naive to the goal of the study, acted as the

11 communicator in the CPT task. All reported normal or corrected-to-normal vision, gave informed

12 consent in accordance with protocols approved by the local ethics committee (Committee on

13 Research Involving Human Subjects, region Arnhem-Nijmegen, The Netherlands), and were offered

14 financial compensation for their time. Seven were excluded due to task performance falling below a

15 pre-defined boundary ( $<70 \%$ trials where the communicator correctly identified the targets), leaving

1631 participants (23 females, mean $\pm \mathrm{SD}=23.7 \pm 3.5$ years old $)$ included in the final analysis. The

17 excluded participants used inadequate strategies, such as simply flipping the stimuli upside-down or

18 left-right instead of engaging in perspective-taking. Although the rejected participants might have

19 been able to use PT2 if we had explicitly instructed to do so, they did not spontaneously used PT2 to

20 solve the task. Given the absence of published effect size estimates for perspective-taking and

21 communicative demands, it was decided to recruit participants until moderate evidence was 
1 obtained for $(\mathrm{BF}=3)$ or against $(\mathrm{BF}=.3)$ main- and interaction-effects of the experimental factors,

2 with a maximum amount of 40 participants (Lee \& Wagenmakers, 2013; Rouder, 2014; Dienes, 2016).

\section{2.2. Experimental Setup}

The experimental setup is illustrated in Fig. 1A and B. A pair of co-players sat at opposite sides of a round wooden table (radius: $120 \mathrm{~cm}$ ). The participant played the role of the communicator; the confederate played the role of the addressee. A set of stimuli (4 digital items next to each other, each item covering $5 \times 5 \mathrm{~cm}^{2}, 7.5 \mathrm{~cm}$ apart, Fig. 1B) was presented along the centre of the main-screen $\left(73 \times 44 \mathrm{~cm}^{2}\right.$; Fig. 1A-a and B) via a projector (DELL M410HD, refresh rate: $60 \mathrm{~Hz}$; Fig. 1A-b) under the table. A barrier (26 cm from the addressee's eyes, Fig. 1A-c) was vertically interposed between the main-screen and the addressee. The barrier consisted of 70 LCD tiles $\left(1 \times 36 \mathrm{~cm}^{2}\right.$ each $)$ arranged along the whole extent of the glass panel. The transparency of each LCD tile could be independently controlled through a computer (transition time: $3.2 \mathrm{msec}$ ). By controlling transparency of each tile we allowed or prevented the addressee from seeing some of the stimuli on the main-screen (manipulation of PT1, Fig. 1B; also see Experiment Task and Design). The upper part $\left(77 \times 14 \mathrm{~cm}^{2}\right)$ of the barrier was covered to prevent eye contact between the co-players. At either side of the base of the barrier, there were two additional small monitors $\left(15.5 \times 8.9 \mathrm{~cm}^{2}\right)$, one facing the communicator (communicator-screen; Fig. 1A-d) and the other the addressee (addressee-screen, Fig. 1A-e). These small monitors allowed us to manipulate communicative demand by showing or not showing the target on the addressee-screen (see Experiment Task and Design). The experimental setup also included a home-key for the communicator (Fig. 1A), aligned with the midline of the communicator and positioned $38 \mathrm{~cm}$ from the centre of the main-screen; a chin-rest for the addressee, aligned with the midline of the addressee and positioned $60 \mathrm{~cm}$ from the centre of the main-screen; and a computer mouse (Fig. 1A-f), held with the right hand of the addressee and which controlled a cursor displayed on the main-screen after the communicator completed the pointing movement and returned to the home-key. 
A

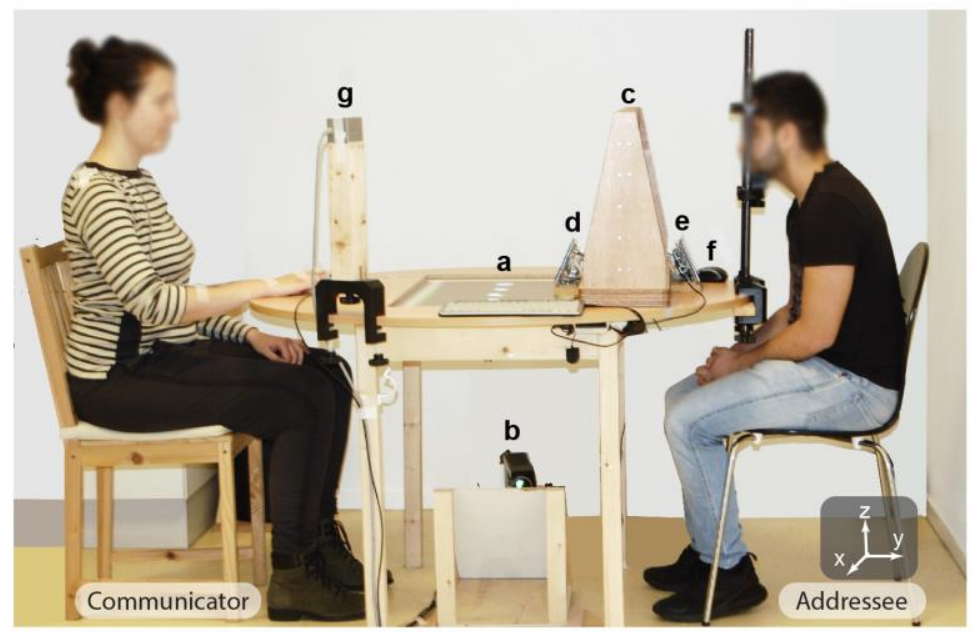

C

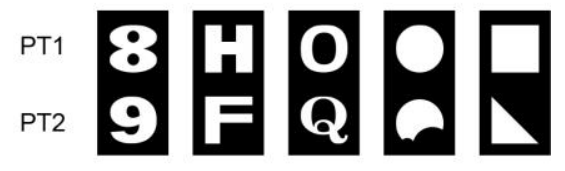

\begin{tabular}{|c|c|c|}
\hline Conditions & $\begin{array}{l}\text { Communicator- } \\
\text { screen }\end{array}$ & $\begin{array}{l}\text { Addressee- } \\
\text { screen }\end{array}$ \\
\hline PT1+NCOM & 8 & 8 \\
\hline PT1+COM & 8 & raven no stom \\
\hline $\mathrm{PT} 2+\mathrm{NCOM}$ & e & e \\
\hline $\mathrm{PT} 2+\mathrm{COM}$ & $\mathcal{e}$ & natsom \\
\hline
\end{tabular}

B

Velocity profile

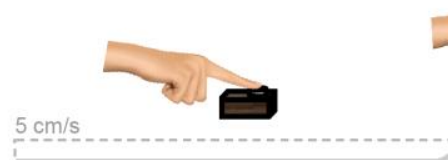

Movement stages

Communicator's
response

Communicator's

perspective

left $\underset{\text { back }}{\stackrel{\text { front }}{\longrightarrow} \text { right }}$

Addressee's

perspective
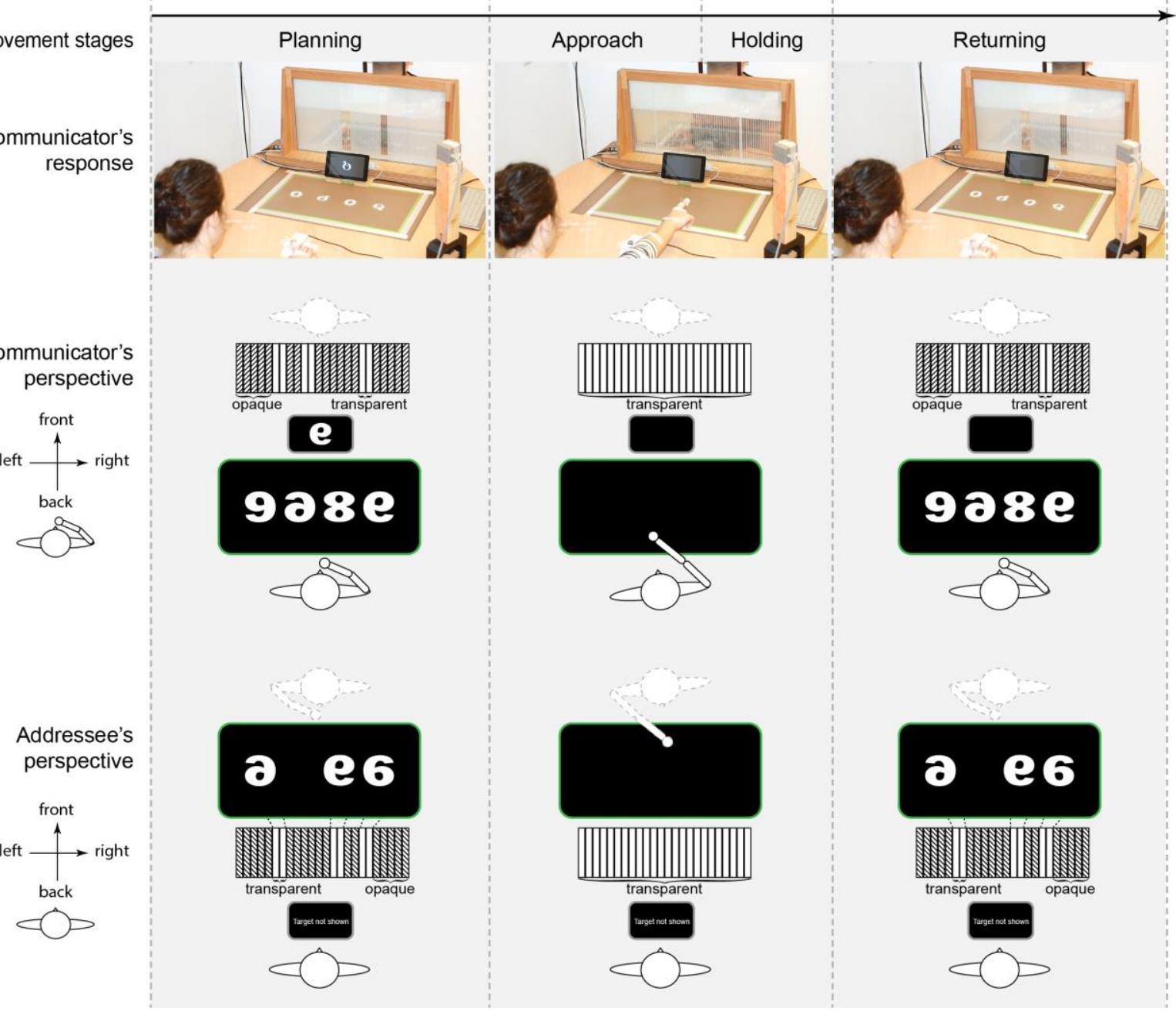
Fig. 1. Experimental settings and design. A. Two co-players sit at the opposite sides of a table. Four stimuli are presented on the main-screen (a) through a projector (b). The communicator (on the left side) needs to point at one of the stimuli, considering which target stimulus can be seen by the addressee through the barrier (c), or which of the visible stimuli look like the target presented on the communicator-screen (d) when seen from the addressee's perspective. Subsequently, the addressee selects a stimulus from the main-screen either based on the communicator's pointing or on the target presented on the addressee-screen (e), by mouse click (f). (g) is the source of the magnetic field used by the motion tracking system. B. The curve indicates a schematic profile of velocity of the pointing finger. Each trial is segmented into four movement stages according to predetermined criteria. The photographs illustrate the corresponding configuration of the experimental setup and the pointing response of the communicator. The last two rows shows a representative trial (PT2+COM condition) illustrating the visual scene available to the communicator (upper row) and to the addressee (bottom row). The large black rectangle represents the main-screen; the small black rectangle represents the communicator-screen (upper row) and the addressee-screen (bottom row). The array of shadowed (opaque) and white (transparent) stripes represents the barrier; the dashed lines between the barrier and the main screen (bottom row) illustrate the addressee's line-of-sight through the transparent parts of the barrier. C. The upper panel shows the visual stimuli with symmetric (PT1) or asymmetric (PT2) features (three other mirrored versions of the stimuli were also adopted in the experiment.). The bottom panel denotes the experimental conditions, arising from using symmetric or asymmetric stimuli (PT1, PT2, respectively) and from showing or not showing the target stimulus on the addressee-screen (NCOM, COM, respectively). More precisely, the communicator-screen presents the target in all trials. The addressee-screen presents the target in the NCOM condition, and the text 'Target not shown' in the COM condition. PT1: Level-1 perspective-taking; PT2: Level-2 perspective-taking; COM: Communicative pointing; NCOM: Non-communicative pointing.

\subsection{Experimental Task and Design}

The CPT task required a communicator to point at one of the four stimuli presented on the mainscreen. A trial started with the communicator pressing and holding on the home-key with the right index finger, making the barrier opaque and a fixation cross to appear on the main-screen. After 1000 msec, portions of the barrier turned transparent and the set of stimuli was displayed on the mainscreen. Meanwhile, a target was presented on the communicator-screen (Fig.1B, Planning). The communicator decided when and where to point, then released the home-key and moved the right hand towards the relevant item on the main-screen, before returning to the home-key. Releasing the

34 home-key triggered the stimuli and target to disappear from the main-screen and from the 35 communicator-screen, and the whole barrier to become transparent (Fig. 1B, Approach and Holding). 
10 of 32

1 No constraints were imposed on the communicator's pointing movement, other than starting from

2 and returning to the home-key, and pointing without touching the main-screen. Once the

3 communicator returned to the home-key, the stimuli reappeared on the main-screen and the barrier

4 became partially opaque as it was at the onset of the trial (Fig.1B, Returning). The addressee could

5 then select an item from the stimuli array on the main-screen with the mouse, triggering the appearance of a grey frame around the selected item, which was also visible to the communicator. After a jittered interval (range: 400 to $600 \mathrm{msec}$, uniform distribution), the next trial would start. We implemented a $2 * 2$ within-subject factorial design (Fig. 1C). First, the CPT task required the

9 communicator to point for either a communicative (COM) or non-communicative (NCOM) purpose.

10 The communicator was informed that the addressee was supposed to select an item that matched 11 the target shown on the addressee-screen, which was identical to the one shown on the 12 communicator-screen. In COM trials, however, the target was shown on the communicator-screen, 13 but not on the addressee-screen. Therefore, the addressee could complete the trial only by observing 14 the communicator's pointing movement; in other words, the communicator was required to instruct 15 the addressee which item should be chosen by pointing. In NCOM trials, the target was shown on 16 both the communicator-screen and the addressee-screen. In these trials, the communicator was 17 asked to predict which item of the stimuli array would be selected by the addressee. COM and NCOM 18 trials were grouped into four testing blocks of 48 trials each, counter-balanced according to an ABBA 19 scheme and the type of the first block was randomly assigned. At the onset of each block of trials, a 20 written instruction was presented on the main-screen (i.e. 'Instruct' for COM blocks, 'Predict' for

21 NCOM blocks), coupled with a red or green frame at the edge of the main-screen throughout the 48

22 trials of a block. The association of the red/green frame with COM/NCOM blocks was randomized 23 across participants, but it was kept consistent within each participant. Second, the communicator 24 was informed that the addressee's choice determined the success of each trial. Therefore, when 25 deciding which item to point at, the communicator needed to adopt the addressee's perspective. The 
communicator needed to consider that the addressee could only select an item that was visible to her, and that matched the target shown on the communicator-screen when seen from the addressee's view. Perspective-taking demand was manipulated through the use of the barrier and of targets with symmetric and asymmetric features. In PT1 trials, the target was symmetric along the horizontal axis (e.g. '8'), so that the target appeared the same from the perspectives of both co-players. However, due to the arrangement of the transparent and opaque elements of the barrier, some items of the stimuli array were visible to both co-players, whereas other items (including at least one '8' as a distractor) were visible only to the communicator. This manipulation was introduced so that the communicator needed to consider which items (only one ' 8 ' is the correct answer) were visible from the addressee's point of view, i.e. to engage in PT1. In PT2 trials, the target was asymmetric (e.g. '9'), so that it

11 appeared different from the communicator's and addressee's perspectives (e.g. a '9' from the communicator's point of view would correspond to a ' 6 ' from the addressee's point of view.). Note that the communicator would not be able to identify the correct item by simply mirroring or flipping 14 the target (e.g. "9" and "6" are not reflected images.) and such strategy would lower their task 15 performance. Furthermore, use of this strategy was discouraged by presenting mirrored versions of 16 the stimuli. Thus, in order to select the correct item, the communicator needed to adopt the 17 addressee's perspective to determine how the target would look, i.e. to engage in PT2. Note that each 18 trial started with a new stimuli configuration such that the communicator needed to engage once 19 more in perspective-taking. To match physical features across stimuli arrays, each trial contained 20 both symmetric and asymmetric stimuli. Targets for the four experimental conditions were 21 counterbalanced across the four stimuli locations on the main-screen. To minimize stereotyped 22 movements, the items were pseudo-randomly arranged such that no more than three trials with 23 targets at the same location on the main-screen were presented in succession. Although the 24 participants only played the role of communicator in the task, they also experienced and understood 25 the role of the addressee during training blocks (see 2.4. Experimental Procedure). 
12 of 32

\subsection{Experimental Procedure}

The experiment started with training blocks in which participants familiarized themselves with the experimental setup and the roles of the CPT task (started as the role of communicator, then altered between the roles). The training blocks consisted of at least 3 blocks of 5 COM trials and 5 NCOM trials. Additional blocks were performed until a block was performed with more than $90 \%$ accuracy when the participant played the role of communicator. In the training blocks, the players alternated in the roles of communicator and addressee, exchanging positions at the table and experiencing both points of view. During the training blocks, the addressee (played by the confederate) performed the NCOM trials by selecting stimuli on the main-screen according to the target shown on the addressee-screen (i.e. the players might select a different item based on their own judgement). Then, during the four testing blocks (separated by self-paced breaks), regardless of the trial conditions, the addressee always selected stimuli indicated by the communicator rather than following the targets presented on the addressee-screen. This procedure ensured that the communicator received exactly matched feedback from the addressee's behaviour across the COM and NCOM conditions. Trial-by-trial and overall accuracy was presented to the players on the mainscreen in training blocks and only overall accuracy was provided at the very end of the testing blocks. Before and after the testing blocks, participants performed 20 pointing movements (baseline trials) to each of the four locations on the main-screen where the stimuli array was displayed, without the presence of the addressee, and with the barrier fully opaque. These measurements provided a baseline reference of each participant's pointing movements in a solo-setting without experimental manipulations.

\subsection{Kinematic Recording and Analysis}

We sampled position and orientation of five sensors at $240 \mathrm{~Hz}$, using an electromagnetic tracking system (LIBERTY, Polhemus). The sensors were attached to the communicator's right index 
1 finger (on the second distal phalanx, on the proximal phalanx, and on the metacarpal joint), wrist

2 (corpus radii), and to the right shoulder. Kinematic data were processed with Kinemagic Toolbox

3 (Verhagen et al., 2012, see also https://github.com/lennartverhagen/kinemagic) using MATLAB

4 R2016b (MathWorks, Natick, MA, USA). The data were filtered using a third-order bidirectional

5 Butterworth low pass filter at a cut-off frequency of $15 \mathrm{~Hz}$. The velocity and acceleration of the index

6 finger were calculated as the first and second derivative of the position. Position was defined within

7 a Euclidian reference system centred on the home-key, with the x-axis along the communicator's

8 transverse plane, the y-axis along the communicator's sagittal plane, and the z-axis along the

9 communicator's coronal plane (The coordinate system is illustrated in the bottom-left panel of Fig.

10 1A). Movement onset-and-offset was defined using a criterion of index fingertip velocity in the

11 sagittal plane (y-z plane) over-or-under $5 \mathrm{~cm} / \mathrm{s}$ for at least $200 \mathrm{msec}$. Hence, each pointing movement

12 was segmented into four stages (Fig. 1B): Planning (or "rest" in some co-speech gestures literature,

13 McNeill, 1992; Kita et al., 1998) -- the period between presentation of the stimuli and movement

14 onset; Approach ("stroke") -- the period between movement onset and arrival near the location of

15 the selected stimulus; Holding ("hold") -- the period between arrival near the selected stimulus and

16 onset of the return movement away from the selected stimulus; and Returning ("retraction") -- from

17 the onset of the return movement until the time the home-key was pressed. Only the first three stages

18 were analysed, since the returning movement does not concern referential pointing and it was

19 constrained by the additional requirement to press the home-key.

20 We examined temporal and spatial aspects of kinematic data. Temporally, we focused on the

21 duration of two movement stages: planning and holding. The spatial features of the pointing

22 movements were quantified as average displacement and variability of the trajectories in three-

23 dimensional space during the approach stage, as indices of movement magnitude and movement

24 correction, respectively (see 1. Introduction). To compare temporal development of spatial features

25 of the movement across participants, each approach trajectory was first normalized into 100 time 
14 of 32

1 points on a participant-level with cubic-spline interpolation. We then extracted time series of average

2 displacement and variability of the trajectories relative to the corresponding values in the baseline

3 movement (performed in the solo-setting). Specifically, for each time point on the time-normalized

4 trajectories, we estimated an ellipsoid along the Eigenbases of the covariance matrix of the

5 trajectories. The centre of the ellipsoid at each time point provided the average position of the

6 pointing finger; the volume of the ellipsoid was computed by taking the $95 \%$ confidence interval of

7 the Mahalanobis distance according to a Chi-square distribution. Based on the ellipsoid at each time

8 point, displacement was calculated as the Euclidian distance from the home-key to the centre of the

9 ellipsoid; and trajectory variability was calculated as the volume of the ellipsoid. Trials with incorrect

10 responses (i.e. pointing movement towards an incorrect item) were excluded from the kinematic

11 analysis (mean: 6.45\%; range: $0.52 \%-17 \%$ ). One participant was excluded from the trajectory

12 analysis because of invalid baseline measuring.

\section{2.6. Statistical Analysis}

To quantify evidence for or against the null hypothesis, we used Bayes Factors (BFs). Stage

15 durations were included into Bayesian repeated-measure ANOVAs in JASP 0.9.2 (JASP Team, 2019)

16 with two factors (perspective-taking and communicative demands) with two levels each. We used a

17 multivariate Cauchy prior with a fixed effects scale factor of $r=.50$, a random effects scale factor of $r$

$18=1$, and a scale covariate of $r=.35$ (Rouder et al., 2012). Post-hoc comparisons were based on the

19 default t-test with a Cauchy (0, r = .71) prior (Rouder et al., 2009). Statistical inferences on the time

20 courses of displacement and trajectory variability were made using non-parametric cluster-based

21 permutation tests (Maris \& Oostenveld, 2007), in order to control for multiple comparisons in the

22 context of data with complex spatiotemporal dependencies. The cluster-forming threshold was $\alpha$

$23=.05$ (two-tailed). P-values corrected for multiple comparisons ( $\mathrm{p}_{\mathrm{MC}}$ ) were computed by ranking the

24 test statistics among sample values from 1000 Monte Carlo runs. We used post-hoc exploration of

25 significant effects to evaluate specific main- and interaction-effects, using a Bonferroni procedure 
1 ( $\mathrm{p}_{\text {corr }}$ ) to correct for multiple comparisons in those pairwise contrasts. These tests were performed

2 with MATLAB R2016b.

3

4 3. Results

5 3.1. Temporal Effects of Perspective-taking and Communicative Demands on the Pointing $6 \quad$ Movements

$7 \quad$ We performed a Bayesian repeated-measure ANOVAs on the duration of three movement stages

8 (planning, approach, and holding). Consistent with our predictions on planning and holding times

9 (see 1. Introduction), the BFs suggested extreme evidence for a main effect of perspective-taking on

10 planning time $(\mathrm{BF}=1.264 \mathrm{e}+21$, Fig. $3 \mathrm{~A})$ and a main effect of communication on holding time $(\mathrm{BF}=$

11 1.960e+3, Fig. 3C). More precisely, participants took longer to initiate a movement during PT2 trials

12 than during PT1 trials $(\mathrm{BF}=2.864 \mathrm{e}+15$; PT2: $4.420 \mathrm{~s}$; PT1: $2.459 \mathrm{~s})$; and held their finger on the end-

13 position location for a longer time at the end of communicative than non-communicative movements

$14(\mathrm{BF}=151.400 ; \mathrm{COM}: .249 \mathrm{~s} ; \mathrm{NCOM}$ :209 s). There was no strong evidence to conclude that approach

15 time differed across conditions (Table 2). 
A

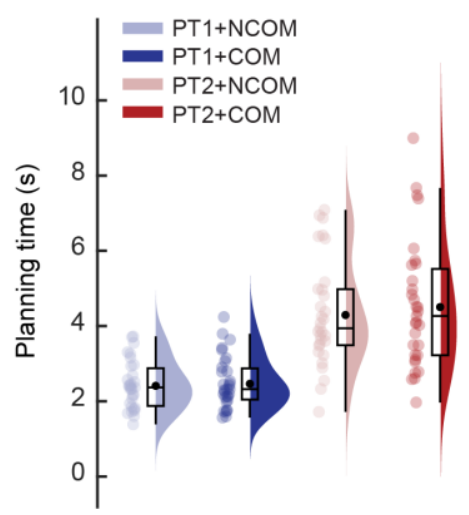

B

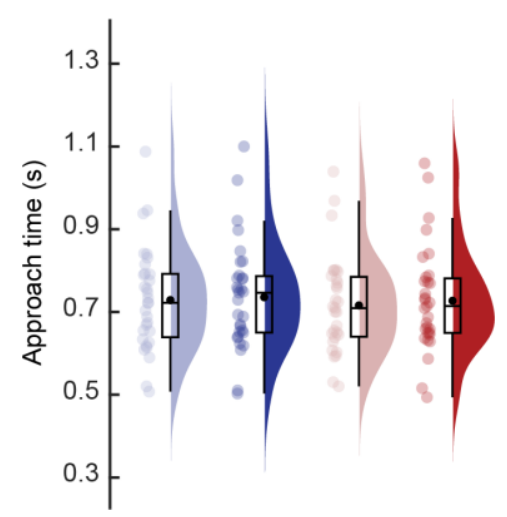

C

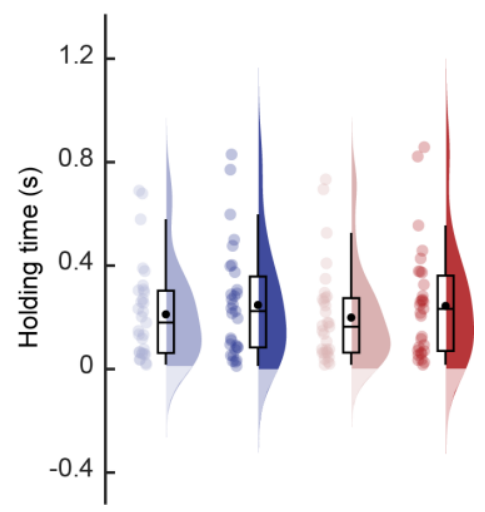

Fig. 2. Temporal features of the pointing movements. Durations of A. planning, B. approach and C. holding stage. The curved areas illustrate kernel density estimates of the data distribution. The coloured dots are jittered raw data and the black dots represent the group mean. The boxes indicate the interquartile range (IQR) and the whiskers are maximum and minimum with 1.5 IQR. The task conditions are coded with the colour of light blue, dark blue, light red and dark red for PT1+NCOM, PT1+COM, PT2+NCOM and PT2+COM, respectively.

Table $2^{\dagger}$

Bayes factors of the effects of perspective-taking and communicative demands and their interaction on the duration of each movement stage (against the null hypothesis).

\begin{tabular}{llll}
\hline Effect (duration) & Planning & Approach & Holding \\
\hline Communication effect & .285 & 2.036 & $1.960 \mathrm{e}+3$ \\
Perspective-taking effect & $1.264 \mathrm{e}+21$ & 4.468 & .272 \\
Interaction effect & .235 & .287 & .297 \\
\hline
\end{tabular}

\section{3}

14

15

16

17

18

19

20

21

22

23

24

25

26 $\dagger$ : Bayes factors $>3$ or $<.3$ provide moderate evidence and $>10$ or $<.1$ strong evidence in favor or against the presence of an experimental effect, respectively (Lee \& Wagenmakers, 2013). 


\subsection{Spatial Effects of Perspective-taking and Communicative Demands on the Pointing} Movements

To compare the spatial dynamics of the pointing movements, we normalized the raw trajectories (Fig. 3A) with respect to equal time intervals per participant. In line with previous findings, displacement of pointing trajectories showed an early effect of communicative demand (from $9 \%$ until $100 \%$ of the approach time, $\mathrm{p}_{\mathrm{MC}}<.001$, Fig. 3B), with longer trajectories in COM than in NCOM trials $\left(\mathrm{t}_{29}=7.531, \mathrm{p}_{\text {corr }}<.001\right.$, Cohen's $\mathrm{d}=1.375$. A post-hoc analysis revealed that the COM trajectories ended further away from the starting position compared to the $\mathrm{NCOM}$ trajectories $(\mathrm{BF}=$ 1.460e+7; COM: $38.14 \mathrm{~cm}$; NCOM: $38.04 \mathrm{~cm}$ ). There was also a main effect of perspective-taking (from $23 \%$ until $100 \%$ of the approach time, $\mathrm{p}_{\mathrm{MC}}<.001$, Fig. 3B), with longer trajectories in PT2 than in PT1 trials $\left(\mathrm{t}_{29}=8.394, \mathrm{p}_{\text {corr }}<.001\right.$, Cohen's $\left.\mathrm{d}=1.533\right)$. A post-hoc analysis revealed that the PT2 trajectories ended further away from the starting position compared to the PT1 trajectories $(\mathrm{BF}=$ 1.019e+13; PT2: $38.18 \mathrm{~cm}$; PT1: $38.00 \mathrm{~cm}$ ). Furthermore, in favour of Hypothesis 3, there was an under-additive interaction between perspective-taking and communicative demands (from 40\% until $85 \%$ of the approach time, $\mathrm{p}_{\mathrm{MC}}<.001, \mathrm{t}_{29}=-5.404, \mathrm{p}_{\mathrm{corr}}<.001$; Cohen's $\mathrm{d}=.987$; Fig. 3B), with a smaller effect of perspective-taking demand (longer trajectories in PT2 than PT1) during COM trials $\left(\mathrm{t}_{29}=4.670, \mathrm{p}_{\text {corr }}=.005\right.$, Cohen's $\left.\mathrm{d}=.853\right)$ than during NCOM trials $\left(\mathrm{t}_{29}=17.344, \mathrm{p}_{\text {corr }}<.001\right.$, Cohen's $d=3.167)$. A Bayesian one-sample t-test suggests that this interaction effect occurred after the initial acceleration phase of the pointing movement $(\mathrm{BF}=6521)$, i.e. after the pointing finger reached peak velocity at approximately 35\% of the approach time. Moreover, these trajectory displacement effects could not be attributed to changes in trajectory variability: the trajectories remained comparable in that respect across conditions throughout the approach time ( $\mathrm{p}_{M C}>.05$, Fig. $\left.3 \mathrm{C}\right)$. A post-hoc analysis contrasted the trajectories of the four task conditions to those of baseline trials (solo-pointing without an addressee). Task-related movements had larger displacements starting around 30\% of the approaching time and afterwards $(39 \%, 32 \%, 32 \%$ and $26 \%$ for NCOM+PT1, NCOM+PT2, 
18 of 32

$\mathrm{COM}+\mathrm{PT} 1$ and $\mathrm{COM}+\mathrm{PT} 2$ respectively). The variability of task-related trajectories were above baseline from $38 \%, 40 \%, 29 \%$ and $25 \%$ of the approaching time and afterwards in NCOM+PT1, $\mathrm{NCOM}+\mathrm{PT} 2, \mathrm{COM}+\mathrm{PT} 1$ and COM+PT2 condition, respectively; Monte Carlo p-values were all smaller than .001 . These results revealed that the mere presence of an addressee had a substantial influence on the organization of the pointing movement, encouraging communicators to move further away from the starting position. We present the group-averaged differential length and differential variability (relative to the baseline per condition) of movement trajectories in Fig. 3 B\&C. Fig.3 A provides an example of raw single-trial trajectories to the four stimuli locations in each of the four conditions and at baseline.

A1

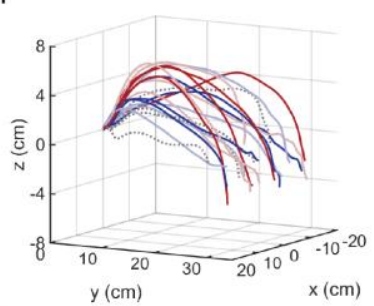

A2

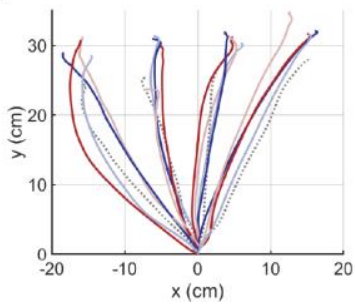

B

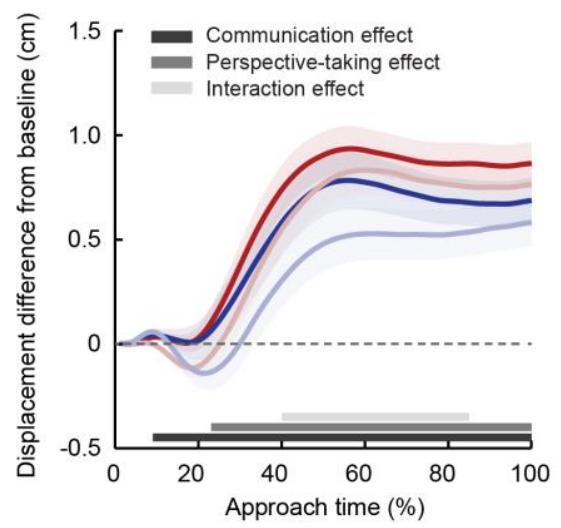

C

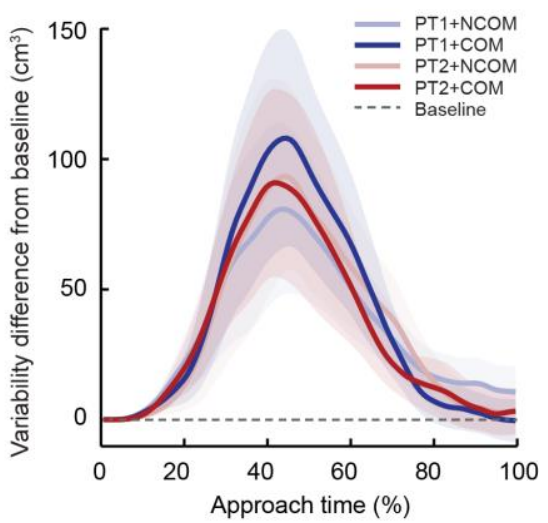

Fig. 3. Spatial features of the pointing movements. A. Illustration of raw pointing trajectories in each experimental condition, both in 3D view (panel A1) and over the horizontal plane (panel A2). Each curve represents a randomly chosen trial from a participant. B. Time courses of the difference in trajectory displacement between task-related and baseline movements, taken as reference (dashed line). Each curve represents group averages; shaded areas indicate \pm 1 SEM over participants. The bars along the $x$-axis indicate significant effects of communicative demand (black bar; between $9 \%$ and $100 \%$ of the approach time, $\mathrm{p}_{\mathrm{MC}}<.001$ ); perspective-taking (dark grey bar; between $23 \%$ and $100 \%$ of the approach time, $\mathrm{p}_{\mathrm{MC}}<.001$ ); and interaction between perspective-taking and communicative demand (light grey bar; between $40 \%$ and $85 \%$ of the approach time, $\mathrm{p}_{\mathrm{MC}}<.001$ ). C. 
1

\section{Discussion}

This study tests whether and how communicative and perspective-taking demands are integrated at the sensorimotor level during referential pointing. The CPT task led communicators to change temporal and spatial features of their pointing movements according to the communicative demand of the task and the spatial perspective of the addressee. In line with previous work, communicators took longer to initiate their movement when inferring how the addressee perceived the referents (PT2) than when discriminating what could be seen by the addressee (PT1) (Michelon \& Zacks, 2006; Kessler \& Rutherford, 2010; Samson et al., 2010; Galati \& Avraamides, 2013; Surtees et al., 2016; Galati et al., 2019). Furthermore, communicators held their finger near the selected stimulus for longer when their pointing movement was required to communicate the target identity to the addressee (Becchio et al., 2010; Cleret de Langavant et al., 2011; Peeters et al., 2015; KrishnanBarman et al., 2017; Murillo Oosterwijk et al., 2017). The novel finding of this study is that the sensorimotor system controls the trajectory of referential pointing by integrating the communicative demands of the task and the spatial perspective of the addressee (Hypothesis 3). Both communicative demand and Level-2 perspective-taking processes influenced motor responses in a similar manner, i.e. lengthened trajectories from an early stage of the pointing movement. Furthermore, the effect of Level-2 perspective-taking on pointing trajectories decreased when communicators conveyed instructive information to addressees (communicative pointing), as compared to when communicators predicted addressees' response (non-communicative pointing). This evidence argues against an alternative possibility, namely, a functional independence between identification of a relevant stimulus according to perspective-taking demands, and movement specification according to communicative demand. This possibility would have resulted in an effect of perspectivetaking limited to the planning stage (Hypothesis 1), or independent effects of perspective-taking and communicative demands during movement execution (Hypothesis 2).

\subsection{Effects of Communicative Demand}


20 of 32

The CPT task effectively modulated the communicative demands experienced by the

communicators; they held their pointing finger near the end-position for longer when they thought the addressee had to identify the correct referent by means of their pointing movements. This observation is consistent with findings from other referential pointing studies (Cleret de Langavant et al., 2011; Murillo Oosterwijk et al., 2017; Peeters et al., 2015; Winner et al., 2019), as well as naturalistic communicative interactions (Clark \& Murphy, 1982; Richardson et al., 2007; Hilbrink et al., 2015; Levinson, 2016). A longer holding time provides a cue that, by virtue of it being longer than necessary and thus instrumentally dysfunctional, ostensively marks the action as communicative (Gredebäck \& Melinder, 2010; Cleret de Langavant et al., 2011; Murillo Oosterwijk et al., 2017; Peeters et al., 2015; Cooney et al., 2018; Winner et al., 2019). Furthermore, a longer holding time allows the addressee to accumulate more sensory evidence about the spatial location of the pointing finger (Bangerter, 2004; Sartori et al., 2009; Sacheli et al., 2013; Vesper et al., 2017). This study also confirms that increasing communicative demand led participants to generate longer movement trajectories, starting shortly after movement onset (Murillo Oosterwijk et al., 2017; Winner et al., 2019). The effect was not a by-product of increased trial-by-trial variability in the movement trajectories, or systematic variations in the end location of the pointing finger. Neither could it be attributed to feedback from the addressee, as the addressee's responses were matched across conditions, i.e. the confederate chose the item indicated by the communicators regardless of the task condition (see 2.4. Experimental Procedure). Moreover, the addressee's face was occluded by the barrier, so that the communicators were unable to make use of social cues, like gaze or facial expressions (see 2.2. Experimental Setup and Fig 1.B). The effect of communicative demand on movement trajectories occurred over and above the systematically longer trajectories and larger variance observed in the joint than in the solo-task settings, across experimental conditions. Taken together, these observations confirm that communicative demand leads to kinematic re-organization of pointing movements (Chu \& Hagoort, 2014; Kita \& Özyürek, 2003), generating a spatially 
exaggerated movement (Becchio et al., 2010; Cleret de Langavant et al., 2011; Krishnan-Barman et al., 2017; Murillo Oosterwijk et al., 2017; Trujillo et al., 2020). These findings raise the possibility that communicative demand leads individuals to change their motor control policy. More precisely, studies of spatially-guided movements have repeatedly shown that participants tested in isolation (as in the solo condition of this study) control, for instance, the end-position of the pointing finger (Todorov \& Jordan, 2003; Nashed et al., 2012; Keyser et al., 2017) and/or minimize spatial variability of the finger position (Wolpert et al., 1994; Harris \& Wolpert, 1998; Wolpert \& Ghahramani, 2000). In contrast, during referential pointing, communicators might focus on trajectory control, leading to a tight integration between communicative demands and sensorimotor trajectory control (Chu \& Hagoort, 2014; Murillo Oosterwijk et al., 2017; Winner et al., 2019).

\subsection{Effects of Perspective-taking}

When solving the CPT task, participants took longer to start their movement during trials that required them to infer how the addressee perceived the referent, in line with the established notion that PT2 requires additional cognitive operations as compared to PT1, e.g. inhibition of one's own perspective, and transformation from an egocentric to an allocentric frames of reference (Michelon \& Zacks, 2006; Kessler \& Rutherford, 2010; Samson et al., 2010; Galati \& Avraamides, 2013; Surtees

17 et al., 2016; Galati et al., 2019). The current study goes further in providing novel evidence of how

18 visuospatial perspective-taking affects spatial features of movement performance. Trials requiring

19 PT2 evoked longer trajectories than trials requiring PT1. The effect started during the initial

20 acceleration phase of the movement, an indication that perspective-taking influences the forward

21 kinematics of a movement (Todorov \& Jordan, 2003; Körding \& Wolpert, 2004; Gallivan et al., 2018).

22 This effect cannot be explained by trajectory adjustments driven by visual feedback of the selected

23 stimulus and its relation to the point of view of the addressee: during performance of the pointing

24 movements, both target and stimuli disappeared from the communicator-screen and the main-

25 screen; and the whole barrier turned transparent. The results also revealed that variability of the 
22 of 32

1 pointing trajectories, indexing movement correction, remained comparable across levels of

2 visuospatial perspective-taking. These observations suggest that the difference in trajectory

3 displacement is due to perspective-taking effects on the initial forward kinematics of the pointing

4 movements, computed during the planning phase before movement onset. It could be argued that

5 this effect of PT2 has a communicative goal, e.g. participants ostensively mark their pointing

6 movements for the addressee. However, this possibility does not explain why perspective-taking

7 demand would lead participants to selectively deploy an ostensive marker on the movement

8 trajectory, but then remove it from the holding time, where there are no differences between the two

9 perspective-taking conditions. This inconsistency in PT2 effects over the approach and holding

10 phases of the movement does not match with the effects of communicative demands, where

11 participants ostensively tag both phases of the movement. Studies on the impact of different frames

12 of reference in coding spatial targets of a movement offer an alternative interpretation of the

13 perspective-taking modulation of trajectory displacement. Specifically, it is possible that the

14 communicators' coding of the location of the selected stimulus was influenced by the use of different

15 frames of reference in perspective-taking conditions. More precisely, an allocentric frame of

16 reference in PT2 trials, i.e. the frame required for estimating how the stimuli were perceived by the

17 addressee. In contrast, communicators could estimate whether the objects could be seen by the

18 addressee (PT1 trials) by using an egocentric frame of reference (Hart \& Moore, 1973; Salatas \&

19 Flavell, 1976; Flavell et al., 1981; Michelon \& Zacks, 2006; Kessler \& Rutherford, 2010; Crawford et

20 al., 2011; Surtees et al., 2013). The sensorimotor system uses those frames of reference when

21 planning and executing a movement (Carrozzo et al., 2002; Chen et al., 2011, 2014; Fiehler et al.,

22 2014; Proulx et al., 2016). In this study, participants aimed their movements at systematically

23 different end-positions in PT1 and PT2, with comparable levels of movement correction (no

24 difference in movement variability), an indication of different initial forward kinematics in the two

25 perspective-taking conditions (Todorov \& Jordan, 2003; Körding \& Wolpert, 2004; Gallivan et al., 
1 2018). Therefore, it could be suggested that the perspective-taking effect on trajectory displacement

2 arises from differences in estimation of the stimulus location due to the different frames of reference

3 used to solve PT1 and PT2 problems.

\subsection{Interaction Between Perspective-taking and Communicative Demands}

The main finding of this study is the under-additive interaction between perspective-taking and communicative demands, indicating that the sensorimotor system makes use of the two types of information in an integrated manner. Communicators lengthened the pointing trajectories after implementing PT2 relative to PT1, but proportionally less when they engaged in intentional communication, i.e. when knowing that the addressee's response depended on their pointing movements. The interaction effect occurred after the initial acceleration phase of the movement, an indication that the interaction is likely to reflect control processes occurring during movement execution (Todorov \& Jordan, 2003; Körding \& Wolpert, 2004; Gallivan et al., 2018). The underadditive nature of the interaction suggests a hierarchical order in how perspective-taking and communicative information are integrated during sensorimotor control. In communicative pointing, the motor controller could privilege the trajectory constraints determined by the distal goal of the movement, i.e. to produce a communicative signal that needs to be correctly interpreted by an addressee. Over-lengthened trajectories, determined by a linear summation of the factors shaping the main effects of perspective-taking and communicative demands, reduce the legibility of the movement (Winner et al., 2019) and increase the noise level in sensorimotor system (Harris \& Wolpert, 1998; Wolpert et al., 2003; Faisal et al., 2008; Scott, 2004, 2016; Schwartz, 2016), thus increase the ambiguity experienced by the addressee when interpreting the observed movement. A motor controller privileging the communicative demands of the movement would imply a reduction of the weight allocated to visuospatial parameters estimated during PT2, i.e. over-estimation of target distance observed in the main effect of perspective-taking. This hypothetical change of control parameters (not only the end-position but also the entire trajectory) would provide communicators 
24 of 32

1 with the means to finely adjust the pointing movement for the addressee, and to follow the Gricean

2 maxim of Quantity (Grice, 1975), i.e. to generate behaviours as informative as required, rather than

3 overly exaggerated displays.

4 Other empirical observations rule out the possibility that the interaction is a generic effect of

5 task difficulty, either from perspective-taking demand before target selection or from communicative

6 demand at the end of pointing movements (holding stage); the interaction effect was limited to a

7 spatial feature of the pointing movements (trajectory displacement), in the context of statistical

8 evidence against similar interactions on temporal features of those movements, throughout planning,

9 approach, and holding phases of the movements. It is also unlikely that the interaction is due to a

10 ceiling effect caused by biomechanical constraints (e.g. the participants could not adequately reach

11 the intended stimulus given their arm length), which should increase as the movement approaches

12 the intended stimulus; in that case, we should have observed stronger interaction effects in the later

13 section of the movement. However, the interaction effect occurred in the middle section of the

14 movement.

\subsection{Interpretational Issues}

The experimental design relies on a previously established operationalization of visuospatial perspective-taking (Surtees et al., 2012, 2013, 2016) and did not include additional conditions to demonstrate that participants considered the distance between an observer and the visual stimulus (PT1), or the angular disparity between a participant and an observer's viewpoints (PT2). The findings of the perspective-taking manipulation are consistent with previous studies that have differentiated PT2 from PT1, but could be tested further by manipulating mental rotation demands in perspective-taking. However, we would like to emphasize that the experimental setup ensures communicators used PT1 and PT2 in the corresponding trials. Namely, due to the varying arrangement of transparent and opaque elements of the barrier, during PT1 trials the communicator needed to consider which of multiple potential stimuli were visible from the addressee's point of 
1 view. Simply pointing to one of the stimuli visible to the communicator was not a viable option.

2 Similarly, during PT2 trials, we used targets that appeared different from the communicator's and

3 addressee's perspectives, and that were intermixed with left-right-mirrored versions. Accordingly,

4 during PT2 trials the communicator needed to adopt the addressee's perspective to determine how

5 the target would look. Simply pointing to the mirror copy of the target was not a viable option (see 2.1. Participants and 2.3. Experimental Task and Design).

It can be seen that participants produced systematically longer trajectories in the joint than in the solo-task settings, across experimental conditions. This observation extends the notion that joint task settings enhance perspective-taking beyond the selection of the correct referent (Freundlieb et al., 2016, 2017), showing that joint-task settings change how participants spatially organize their

11 movements (Creem-Regehr et al., 2013; Proffitt \& Linkenauger, 2013; Ciardo et al., 2016; Proulx et 12 al., 2016; Ondobaka et al., 2017; Coello et al., 2018).

It could be argued that because the task involved several repetitions of the same movements,

14 the participants might have produced stereotypical responses that are qualitatively different from 15 the occasional referential pointing movements occurring during daily communicative interactions. 16 However, participants systematically and spontaneously produced more ostensive movements 17 during communicative than non-communicative trials, and those differences did not change during 18 the course of the experiment, an indication that participants remained sensitive to the 19 communicative demand of the task throughout the study. However, it remains to be seen whether 20 the current findings, obtained in the context of highly controlled experimental conditions, can be 21 generalized to settings involving the same fundamental phenomenon, but more communicative 22 options, as during natural dialogue with co-speech gestures.

23 It could also be argued that the use of a confederate might introduce biases in the findings, 24 similar to those reported during face-to-face dialogue (Kuhlen \& Brennan, 2013). However, the 25 current settings involve non-verbal stereotyped responses with considerably fewer degrees of 
26 of 32

1 freedom than multimodal utterances in spoken dialogue. Furthermore, there was no demand on the

2 confederates to deceive the participants, nor possibilities for the confederates to provide their

3 response in a different manner. Accordingly, the minimal risks of using a confederate in the current

4 circumstances should be weighed against the interpretational advantage of excluding differences in

5 the behaviour of the addressee as a source of experimental effects.

\section{Conclusions}

This study provides evidence that the sensorimotor system makes use of communicative and

9 perspective-taking information in planning and controlling pointing trajectories, suggesting that

10 during movement execution, communicative constraints are prioritized over the spatial biases

11 evoked by perspective-taking. This observation indicates that perspective-taking and communicative

12 demands share a common coding in the sensorimotor interface, allowing those different cognitive

13 demands to be integrated during movement execution. The finding contributes to understanding the

14 interface between sensorimotor and conceptual abilities in humans, showing that communicative

15 and perspective-taking knowledge penetrates the sensorimotor system. Put differently,

16 sensorimotor processes are not a simple production mechanism, downstream to and encapsulated

17 from cognitive decisions. This observation has consequences for models of human communication.

18 It implies that the format of communicative and perspective-taking knowledge needs to be

19 commensurate with the movement dynamics controlled by the sensorimotor system. The current

20 study highlights the value of bridging largely separated research traditions in sensorimotor control

21 and human communicative behaviour, including co-speech gestures and other referential actions,

22 and it opens the way for studying neural mechanisms integrating other agents' knowledge into

23 communicators' behaviour under controlled yet ecologically-relevant experimental conditions. 


\section{Acknowledgements}

This work was supported by the research program Language in Interaction, financed by the Netherlands Organization for Scientific Research (NWO). R. Liu was supported by a grant from the China Scholarship Council (CSC; 201604910514). The authors would like to thank Gabriela Forgione for helping with data acquisition.

\section{References}

Bangerter, A. (2004). Using Pointing and Describing to Achieve Joint Focus of Attention in Dialogue. Psychological Science, 15(6), 415-419. https://doi.org/10.1111/j.0956-7976.2004.00694.x

Barr, D. J. (2008). Pragmatic expectations and linguistic evidence: Listeners anticipate but do not integrate common ground. Cognition, 109(1), 18-40. https://doi.org/10.1016/j.cognition.2008.07.005

Bays, P. M., \& Wolpert, D. M. (2007). Computational principles of sensorimotor control that minimize uncertainty and variability. The Journal of Physiology, 578(2), 387-396. https://doi.org/10.1113/jphysiol.2006.120121

Becchio, C., Sartori, L., \& Castiello, U. (2010). Toward You: The Social Side of Actions. Current Directions in Psychological Science, 19(3), 183-188. https://doi.org/10.1177/0963721410370131

Blokpoel, M., van Kesteren, M., Stolk, A., Haselager, P., Toni, I., \& Van Rooij, I. (2012). Recipient design in human communication: simple heuristics or perspective taking? Frontiers in Human Neuroscience, 6. https://doi.org/10.3389/fnhum.2012.00253

Brown-Schmidt, S., \& Hanna, J. (2011). Talking in another persons shoes: Incremental perspectivetaking in language processing. Dialogue \& Discourse, 2(1), 11-33. https://doi.org/10.5087/dad.2011.102

Carrozzo, M., Stratta, F., McIntyre, J., \& Lacquaniti, F. (2002). Cognitive allocentric representations of visual space shape pointing errors. Experimental Brain Research, 147(4), 426-436. https://doi.org/10.1007/s00221-002-1232-4

Chen, Y., Byrne, P., \& Crawford, J. D. (2011). Time course of allocentric decay, egocentric decay, and allocentric-to-egocentric conversion in memory-guided reach. Neuropsychologia, 49(1), 4960. https://doi.org/10.1016/j.neuropsychologia.2010.10.031

Chen, Y., Monaco, S., Byrne, P., Yan, X., Henriques, D. Y. P., \& Crawford, J. D. (2014). Allocentric versus egocentric representation of remembered reach targets in human cortex. The Journal of Neuroscience, 34(37), 12515-12526. https://doi.org/10.1523/JNEUROSCI.1445-14.2014

Chu, M., \& Hagoort, P. (2014). Synchronization of speech and gesture: Evidence for interaction in action. Journal of Experimental Psychology: General, 143(4), 1726-1741. https://doi.org/10.1037/a0036281

Ciardo, F., Lugli, L., Nicoletti, R., Rubichi, S., \& Iani, C. (2016). Action-space coding in social contexts. Scientific Reports, 6, 22673. https://doi.org/10.1038/srep22673 
28 of 32

Clark, H. H., \& Murphy, G. L. (1982). Audience Design in Meaning and Reference. In J.-F. Le Ny \& W. Kintsch (Eds.), Advances in Psychology (Vol. 9, pp. 287-299). North-Holland. https://doi.org/10.1016/S0166-4115(09)60059-5

Clements-Stephens, A. M., Vasiljevic, K., Murray, A. J., \& Shelton, A. L. (2013). The role of potential agents in making spatial perspective taking social. Frontiers in Human Neuroscience, 7, 497. https://doi.org/10.3389/fnhum.2013.00497

Cleret de Langavant, L., Remy, P., Trinkler, I., McIntyre, J., Dupoux, E., Berthoz, A., \& Bachoud-Lévi, A.-C. (2011). Behavioral and neural correlates of communication via pointing. PloS One, 6(3), e17719. https://doi.org/10.1371/journal.pone.0017719

Coello, Y., Quesque, F., Gigliotti, M.-F., Ott, L., \& Bruyelle, J.-L. (2018). Idiosyncratic representation of peripersonal space depends on the success of one's own motor actions, but also the successful actions of others! PLoS ONE, 13(5). https://doi.org/10.1371/journal.pone.0196874

Cooney, S. M., Brady, N., \& McKinney, A. (2018). Pointing perception is precise. Cognition, 177, 226233. https://doi.org/10.1016/j.cognition.2018.04.021

Cooperrider, K. (2016). The Co-Organization of Demonstratives and Pointing Gestures. Discourse Processes, 53(8), 632-656. https://doi.org/10.1080/0163853X.2015.1094280

Crawford, J. D., Henriques, D. Y. P., \& Medendorp, W. P. (2011). Three-dimensional transformations for goal-directed action. Annual Review of Neuroscience, 34, 309-331. https://doi.org/10.1146/annurev-neuro-061010-113749

Creem-Regehr, S. H., Gagnon, K. T., Geuss, M. N., \& Stefanucci, J. K. (2013). Relating spatial perspective taking to the perception of other's affordances: providing a foundation for predicting the future behavior of others. Frontiers in Human Neuroscience, 7. https://doi.org/10.3389/fnhum.2013.00596

de Ruiter, J. P. (2000). The production of gesture and speech. In D. McNeill (Ed.), Language and Gesture (pp. 284-311). Cambridge University Press. https://doi.org/10.1017/CB09780511620850.018

de Ruiter, J. P., Bangerter, A., \& Dings, P. (2012). The Interplay Between Gesture and Speech in the Production of Referring Expressions: Investigating the Tradeoff Hypothesis. Topics in Cognitive Science, 4(2), 232-248. https://doi.org/10.1111/j.1756-8765.2012.01183.x

Dienes, Z. (2016). How Bayes factors change scientific practice. Journal of Mathematical Psychology, 72, 78-89. https://doi.org/10.1016/j.jmp.2015.10.003

Enfield, N. J., Kita, S., \& de Ruiter, J. P. (2007). Primary and secondary pragmatic functions of pointing gestures. Journal of Pragmatics, 39(10), 1722-1741. https://doi.org/10.1016/j.pragma.2007.03.001

Enfield, N. J., \& Sidnell, J. (2017). The Concept of Action. Cambridge University Press. https://doi.org/10.1017/9781139025928

Faisal, A. A., Selen, L. P. J., \& Wolpert, D. M. (2008). Noise in the nervous system. Nature Reviews. Neuroscience, 9(4), 292-303. https://doi.org/10.1038/nrn2258

Fiehler, K., Wolf, C., Klinghammer, M., \& Blohm, G. (2014). Integration of egocentric and allocentric information during memory-guided reaching to images of a natural environment. Frontiers in Human Neuroscience, 8. https://doi.org/10.3389/fnhum.2014.00636 
Flavell, J. H., Everett, B. A., Croft, K., \& Flavell, E. R. (1981). Young children's knowledge about visual perception: Further evidence for the Level 1-Level 2 distinction. Developmental Psychology, 17(1), 99-103. https://doi.org/10.1037/0012-1649.17.1.99

Freundlieb, M., Kovács, Á. M., \& Sebanz, N. (2016). When do humans spontaneously adopt another's visuospatial perspective? Journal of Experimental Psychology. Human Perception and Performance, 42(3), 401-412. https://doi.org/10.1037/xhp0000153

Freundlieb, M., Sebanz, N., \& Kovács, Á. M. (2017). Out of your sight, out of my mind: Knowledge about another person's visual access modulates spontaneous visuospatial perspectivetaking. Journal of Experimental Psychology. Human Perception and Performance, 43(6), 1065-1072. https://doi.org/10.1037/xhp0000379

Galati, A., \& Avraamides, M. N. (2013). Flexible spatial perspective-taking: conversational partners weigh multiple cues in collaborative tasks. Frontiers in Human Neuroscience, 7, 618. https://doi.org/10.3389/fnhum.2013.00618

Galati, A., Dale, R., \& Duran, N. D. (2019). Social and configural effects on the cognitive dynamics of perspective-taking. Journal of Memory and Language, 104, 1-24. https://doi.org/10.1016/j.jml.2018.08.007

Gallivan, J. P., Chapman, C. S., Wolpert, D. M., \& Flanagan, J. R. (2018). Decision-making in sensorimotor control. Nature Reviews Neuroscience, 19(9), 519-534. https://doi.org/10.1038/s41583-018-0045-9

Gredebäck, G., \& Melinder, A. (2010). The development and neural basis of pointing comprehension. Social Neuroscience, 5(5-6), 441-450. https://doi.org/10.1080/17470910903523327

Grice, P. (1975). Logic and conversation. In J. Morgan \& P. Cole (Eds.), Syntax and semantic Vol. 3: Speech acts (Vol. 3, pp. 41-58). Academic Press. http://lefft.xyz/psycholingAU16/readings/grice1975-logic-and-conversation.pdf

Harris, C. M., \& Wolpert, D. M. (1998). Signal-dependent noise determines motor planning. Nature, 394(6695), 780-784. https://doi.org/10.1038/29528

Hart, R. A., \& Moore, G. T. (1973). The Development of Spatial Cognition: A Review. In Image \& environment: Cognitive mapping and spatial behavior (pp. 246-288). AldineTransaction.

Hilbrink, E. E., Gattis, M., \& Levinson, S. C. (2015). Early developmental changes in the timing of turn-taking: a longitudinal study of mother-infant interaction. Frontiers in Psychology, 6. https://doi.org/10.3389/fpsyg.2015.01492

JASP Team. (2019). JASP(Version 0.9.2) [Computer software].

Kessler, K., \& Rutherford, H. (2010). The Two Forms of Visuo-Spatial Perspective Taking are Differently Embodied and Subserve Different Spatial Prepositions. Frontiers in Psychology, 1. https://doi.org/10.3389/fpsyg.2010.00213

Keysar, B., Barr, D. J., Balin, J. A., \& Brauner, J. S. (2000). Taking Perspective in Conversation: The Role of Mutual Knowledge in Comprehension. Psychological Science, 11(1), 32-38. https://doi.org/10.1111/1467-9280.00211

Keyser, J., Medendorp, W. P., \& Selen, L. P. J. (2017). Task-dependent vestibular feedback responses in reaching. Journal of Neurophysiology, 118(1), 84-92. https://doi.org/10.1152/jn.00112.2017

Kita, S., Gijn, I. van, \& Hulst, H. van der. (1998). Movement phases in signs and co-speech gestures, and their transcription by human coders. In I. Wachsmuth \& M. Fröhlich (Eds.), Gesture and 
30 of 32

sign language in human-computer interaction : international gesture workshop Bielefeld, Germany, September 17-19, 1997 : proceedings (pp. 23-35). Springer. http://dx.doi.org/10.1007/BFb0052986

Kita, S., \& Özyürek, A. (2003). What does cross-linguistic variation in semantic coordination of speech and gesture reveal?: Evidence for an interface representation of spatial thinking and speaking. Journal of Memory and Language, 48(1), 16-32. https://doi.org/10.1016/S0749596X(02)00505-3

Körding, K. P., \& Wolpert, D. M. (2004). Bayesian integration in sensorimotor learning. Nature, 427(6971), 244-247. https://doi.org/10.1038/nature02169

Körding, K. P., \& Wolpert, D. M. (2006). Bayesian decision theory in sensorimotor control. Trends in Cognitive Sciences, 10(7), 319-326. https://doi.org/10.1016/j.tics.2006.05.003

Krishnan-Barman, S., Forbes, P. A. G., \& Hamilton, A. F. de C. (2017). How can the study of action kinematics inform our understanding of human social interaction? Neuropsychologia, 105, 101-110. https://doi.org/10.1016/j.neuropsychologia.2017.01.018

Kuhlen, A. K., \& Brennan, S. E. (2013). Language in dialogue: when confederates might be hazardous to your data. Psychonomic Bulletin \& Review, 20(1), 54-72. https://doi.org/10.3758/s13423-012-0341-8

Lee, M. D., \& Wagenmakers, E.-J. (2013). Bayesian cognitive modeling: A practical course. Cambridge University Press. https://doi.org/10.1017/CB09781139087759

Levinson, S. C. (2016). Turn-taking in Human Communication - Origins and Implications for Language Processing. Trends in Cognitive Sciences, 20(1), 6-14. https://doi.org/10.1016/j.tics.2015.10.010

Liszkowski, U., Brown, P., Callaghan, T., Takada, A., \& de Vos, C. (2012). A prelinguistic gestural universal of human communication. Cognitive Science, 36(4), 698-713. https://doi.org/10.1111/j.1551-6709.2011.01228.x

Maris, E., \& Oostenveld, R. (2007). Nonparametric statistical testing of EEG- and MEG-data. Journal of Neuroscience Methods, 164(1), 177-190. https://doi.org/10.1016/j.jneumeth.2007.03.024

McNeill, D. (1992). Hand and Mind: What Gestures Reveal about Thought. University of Chicago Press.

Michelon, P., \& Zacks, J. M. (2006). Two kinds of visual perspective taking. Attention, Perception, \& Psychophysics, 68(2), 327-337.

Murillo Oosterwijk, A., Boer, M. de, Stolk, A., Hartmann, F., Toni, I., \& Verhagen, L. (2017). Communicative knowledge pervasively influences sensorimotor computations. Scientific Reports, 7(1), 4268. https://doi.org/10.1038/s41598-017-04442-w

Nashed, J. Y., Crevecoeur, F., \& Scott, S. H. (2012). Influence of the behavioral goal and environmental obstacles on rapid feedback responses. Journal of Neurophysiology, 108(4), 999-1009. https://doi.org/10.1152/jn.01089.2011

Ondobaka, S., Kilner, J., \& Friston, K. (2017). The role of interoceptive inference in theory of mind. Brain and Cognition, 112, 64-68. https://doi.org/10.1016/j.bandc.2015.08.002

Özyürek, A. (2002). Do Speakers Design Their Cospeech Gestures for Their Addressees? The Effects of Addressee Location on Representational Gestures. Journal of Memory and Language, 46(4), 688-704. https://doi.org/10.1006/jmla.2001.2826 
Peeters, D., Chu, M., Holler, J., Hagoort, P., \& Özyürek, A. (2015). Electrophysiological and Kinematic Correlates of Communicative Intent in the Planning and Production of Pointing Gestures and Speech. Journal of Cognitive Neuroscience, 27(12), 2352-2368. https://doi.org/10.1162/jocn_a_00865

Pezzulo, G., Iodice, P., Ferraina, S., \& Kessler, K. (2013). Shared action spaces: a basis function framework for social re-calibration of sensorimotor representations supporting joint action. Frontiers in Human Neuroscience, 7. https://doi.org/10.3389/fnhum.2013.00800

Pouw, W., Trujillo, J. P., \& Dixon, J. A. (2020). The quantification of gesture-speech synchrony: A tutorial and validation of multimodal data acquisition using device-based and video-based motion tracking. Behavior Research Methods, 52(2), 723-740. https://doi.org/10.3758/s13428-019-01271-9

Proffitt, D. R., \& Linkenauger, S. A. (2013). Perception Viewed as a Phenotypic Expression. In Action Science: Foundations of an Emerging Discipline. The MIT Press.

Proulx, M. J., Todorov, O. S., Taylor Aiken, A., \& de Sousa, A. A. (2016). Where am I? Who am I? The Relation Between Spatial Cognition, Social Cognition and Individual Differences in the Built Environment. Frontiers in Psychology, 7. https://doi.org/10.3389/fpsyg.2016.00064

Richardson, D. C., Dale, R., \& Kirkham, N. Z. (2007). The art of conversation is coordination: common ground and the coupling of eye movements during dialogue. Psychological Science, 18(5), 407-413. https://doi.org/10.1111/j.1467-9280.2007.01914.x

Rouder, J. N. (2014). Optional stopping: No problem for Bayesians. Psychonomic Bulletin \& Review, 21(2), 301-308. https://doi.org/10.3758/s13423-014-0595-4

Rouder, J. N., Morey, R. D., Speckman, P. L., \& Province, J. M. (2012). Default Bayes factors for ANOVA designs. Journal of Mathematical Psychology, 56(5), 356-374. https://doi.org/10.1016/j.jmp.2012.08.001

Rouder, J. N., Speckman, P. L., Sun, D., Morey, R. D., \& Iverson, G. (2009). Bayesian t tests for accepting and rejecting the null hypothesis. Psychonomic Bulletin \& Review, 16(2), 225-237. https://doi.org/10.3758/PBR.16.2.225

Sacheli, L. M., Tidoni, E., Pavone, E. F., Aglioti, S. M., \& Candidi, M. (2013). Kinematics fingerprints of leader and follower role-taking during cooperative joint actions. Experimental Brain Research, 226(4), 473-486. https://doi.org/10.1007/s00221-013-3459-7

Salatas, H., \& Flavell, J. H. (1976). Perspective Taking: The Development of Two Components of Knowledge. Child Development, 47(1), 103-109. https://doi.org/10.2307/1128288

Samson, D., Apperly, I. A., Braithwaite, J. J., Andrews, B. J., \& Bodley Scott, S. E. (2010). Seeing it their way: evidence for rapid and involuntary computation of what other people see. Journal of Experimental Psychology. Human Perception and Performance, 36(5), 1255-1266. https://doi.org/10.1037/a0018729

Sartori, L., Becchio, C., Bara, B. G., \& Castiello, U. (2009). Does the intention to communicate affect action kinematics? Consciousness and Cognition, 18(3), 766-772. https://doi.org/10.1016/j.concog.2009.06.004

Schwartz, A. B. (2016). Movement: How the Brain Communicates with the World. Cell, 164(6), 1122-1135. https://doi.org/10.1016/j.cell.2016.02.038

Scott, S. H. (2004). Optimal feedback control and the neural basis of volitional motor control. Nature Reviews Neuroscience, 5(7), 532-545. https://doi.org/10.1038/nrn1427 
32 of 32

Scott, S. H. (2016). A Functional Taxonomy of Bottom-Up Sensory Feedback Processing for Motor Actions. Trends in Neurosciences, 39(8), 512-526. https://doi.org/10.1016/j.tins.2016.06.001

Surtees, A., Apperly, I., \& Samson, D. (2013). Similarities and differences in visual and spatial perspective-taking processes. Cognition, 129(2), 426-438. https://doi.org/10.1016/j.cognition.2013.06.008

Surtees, A., Apperly, I., \& Samson, D. (2016). I've got your number: Spontaneous perspective-taking in an interactive task. Cognition, 150, 43-52. https://doi.org/10.1016/j.cognition.2016.01.014

Surtees, A., Butterfill, S., \& Apperly, I. (2012). Direct and indirect measures of Level-2 perspectivetaking in children and adults. The British Journal of Developmental Psychology, 30(Pt 1), 7586. https://doi.org/10.1111/j.2044-835X.2011.02063.x

Todorov, E., \& Jordan, M. I. (2002). Optimal feedback control as a theory of motor coordination. Nature Neuroscience, 5(11), 1226-1235. https://doi.org/10.1038/nn963

Todorov, E., \& Jordan, M. I. (2003). A Minimal Intervention Principle for Coordinated Movement. In S. Becker, S. Thrun, \& K. Obermayer (Eds.), Advances in Neural Information Processing Systems 15 (pp. 27-34). MIT Press. http://papers.nips.cc/paper/2195-a-minimalintervention-principle-for-coordinated-movement.pdf

Tomasello, M. (2008). Origins of human communication. The MIT Press.

Tomasello, M., Carpenter, M., \& Liszkowski, U. (2007). A new look at infant pointing. Child Development, 78(3), 705-722. https://doi.org/10.1111/j.1467-8624.2007.01025.x

Trujillo, J. P., Simanova, I., Özyürek, A., \& Bekkering, H. (2020). Seeing the Unexpected: How Brains Read Communicative Intent through Kinematics. Cerebral Cortex (New York, N.Y.: 1991), 30(3), 1056-1067. https://doi.org/10.1093/cercor/bhz148

Verhagen, L., Dijkerman, H. C., Medendorp, W. P., \& Toni, I. (2012). Cortical Dynamics of Sensorimotor Integration during Grasp Planning. Journal of Neuroscience, 32(13), 45084519. https://doi.org/10.1523/JNEUROSCI.5451-11.2012

Vesper, C., Schmitz, L., \& Knoblich, G. (2017). Modulating action duration to establish nonconventional communication. Journal of Experimental Psychology. General, 146(12), 1722-1737. https://doi.org/10.1037/xge0000379

Winner, T., Selen, L., Murillo Oosterwijk, A., Verhagen, L., Medendorp, W. P., van Rooij, I., \& Toni, I. (2019). Recipient Design in Communicative Pointing. Cognitive Science, 43(5), e12733. https://doi.org/10.1111/cogs.12733

Wolpert, D. M., Doya, K., \& Kawato, M. (2003). A unifying computational framework for motor control and social interaction. Philosophical Transactions of the Royal Society B-Biological Sciences, 358(1431), 593-602. https://doi.org/10.1098/rstb.2002.1238

Wolpert, D. M., \& Ghahramani, Z. (2000). Computational principles of movement neuroscience. Nature Neuroscience, 3(11), 1212-1217. https://doi.org/10.1038/81497

Wolpert, D. M., Ghahramani, Z., \& Jordan, M. I. (1994). Perceptual distortion contributes to the curvature of human reaching movements. Experimental Brain Research, 98(1), 153-156. 